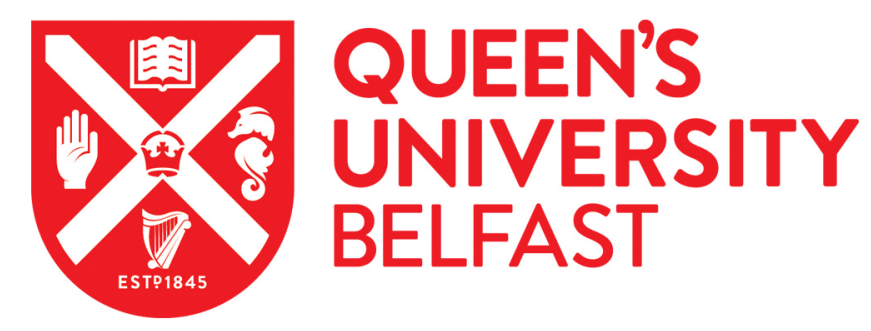

\title{
Disability as a predictor of breast cancer screening uptake: $A$ population-based study of 57,328 women
}

Ross, E., Maguire, A., Donnelly, M., Mairs, A., Hall, C., \& O'Reilly, D. (2019). Disability as a predictor of breast cancer screening uptake: A population-based study of 57,328 women. Journal of Medical Screening. https://doi.org/10.1177/0969141319888553

Published in:

Journal of Medical Screening

Document Version:

Peer reviewed version

Queen's University Belfast - Research Portal:

Link to publication record in Queen's University Belfast Research Portal

Publisher rights

( 2019 The Authors. This work is made available online in accordance with the publisher's policies. Please refer to any applicable terms of use of the publisher.

\section{General rights}

Copyright for the publications made accessible via the Queen's University Belfast Research Portal is retained by the author(s) and / or other copyright owners and it is a condition of accessing these publications that users recognise and abide by the legal requirements associated with these rights.

Take down policy

The Research Portal is Queen's institutional repository that provides access to Queen's research output. Every effort has been made to ensure that content in the Research Portal does not infringe any person's rights, or applicable UK laws. If you discover content in the Research Portal that you believe breaches copyright or violates any law, please contact openaccess@qub.ac.uk. 
Full Title: Physical disability as a predictor of breast cancer screening uptake: a populationbased study of 57,328 women.

Short Title: Physical disability and breast cancer screening uptake.

\section{Authors and Affiliations:}

Emma Ross ${ }^{1}$, Aideen Maguire ${ }^{1}$, Michael Donnelly ${ }^{1}$, Adrian Mairs ${ }^{2}$, Clare Hall ${ }^{2}$, Dermot O'Reilly ${ }^{1}$

${ }^{1}$ Centre for Public Health, Queen's University Belfast, Belfast, Northern Ireland

${ }^{2}$ Public Health Agency, Belfast, Northern Ireland

\section{Declarations of conflicting interest: None}

Correspondence to:

Dr Emma Ross

Centre for Public Health;

Queen's University Belfast;

Belfast BT12 6BJ,

Northern Ireland

Email: E.Ross@qub.ac.uk 


\begin{abstract}
Objective: There is a growing body of evidence suggesting inequalities in breast cancer screening uptake in the United States (US) for women with disabilities, yet few attempts have been made to examine whether this association applies to the United Kingdom (UK). We conducted the first population-wide study investigating the impact of physical disability on uptake of breast cancer screening in Northern Ireland.
\end{abstract}

Methods: Breast screening records extracted from the National Breast Screening System (NBSS) were linked to the Northern Ireland Longitudinal Study (NILS). This identified a cohort of 57,328 women who were followed through one complete three-year screening cycle of the National Health Service Breast Screening Programme (NHSBSP) in Northern Ireland. The presence of disability was identified from responses to the 2011 Census.

Results: $35.8 \%$ of women reported having at least one chronic physical disability and these individuals were $7 \%$ less likely to attend compared to those with no physical disability (OR $0.93 ; 95 \%$ CI 0.89 to 0.98 ). Variation in the degree of disparity observed was evident according to the type and number of comorbid disabilities examined.

Conclusion: This is the first population-wide study in Northern Ireland to identify disparities in breast screening uptake for women with chronic physical disabilities, in particular, those with multimorbidity. This is of particular concern given the projected rise in the prevalence of disability associated with the ageing population. 


\section{Introduction}

Breast cancer now represents the most common cancer in the United Kingdom (UK), accounting for $15 \%$ of all new cases of cancer diagnosed each year. ${ }^{1}$ Early diagnosis through routine screening of the at-risk population remains the gold-standard method of detecting breast cancer and reducing the mortality associated with the disease. ${ }^{2}$ Since the implementation of the National Health Service Breast Screening Programme (NHSBSP) in 1988, there has been some controversy surrounding the potential harms of the programme, however, an independent review of the NHSBSP commissioned by the Department of Health and Cancer Research UK concluded that the $20 \%$ reduction in breast cancer mortality far outweighs the potential harms associated with routine screening. ${ }^{2}$ However, the overall efficacy of the programme and the subsequent gain in terms of mortality benefit is reliant on maintaining high rates of participation. Although there is some regional variation, approximately $74 \%$ of women in the UK attend breast screening every year. ${ }^{3}$ Whilst this figure exceeds the UK minimum standard (70\%), uptake remains below the national target of $80 \%$ and this has been identified as a central factor contributing to avoidable cancer deaths. ${ }^{4}$

In recent years, considerable research efforts have been invested in examining the underlying determinants of participation in breast cancer screening. ${ }^{5-10}$ Although the vast majority of studies focus on the impact of socio-demographic factors on breast screening uptake, there is some evidence implicating poor physical health as a key determinant of screening behaviour. ${ }^{7}$ In particular, a growing body of evidence suggests that women with disability are significantly less likely to participate in breast screening. ${ }^{1-16}$ This is not unexpected given the extensive literature indicating that despite an ever-increasing awareness of the elevated incidence of chronic illness in individuals with disability amongst healthcare professionals, these individuals experience inequalities in many other aspects of healthcare service utilisation, including preventative cervical cancer screening ${ }^{17-20}$, and oral health services ${ }^{19,21}$. There are several potential mechanisms through which physical disability may contribute to reduced participation in breast screening, many of which relate to the additional physical barriers to attending screening. These include factors such as difficulty obtaining suitable transport to screening appointments, lack of accessibility at screening centres, and difficulty standing unaided during screening. ${ }^{22}$ Additionally, the increased levels of social deprivation among those with disabilities may, to some extent, contribute further to inequalities in uptake, given that social deprivation has been previously linked to reduced breast screening uptake. ${ }^{7,8,23,24}$ Although there are currently no meta-analyses or systematic reviews attempting 
to summarise the evidence between disability and breast cancer screening uptake, the available evidence has been narratively reviewed by Andresen et al. ${ }^{12}$ In three of the five studies included in this review, attendance at breast screening was significantly lower for women with disability. ${ }^{13,18,25}$ However, the authors noted that considerable methodological heterogeneity and an inability to universally control for confounding factors, particularly social determinants such as socio-economic status, cause difficulty in making reliable inferences from the results and hinder the generalisability of these studies. Additionally, although there is a growing body of research examining this association in the United States (US), there is a dearth of studies investigating this relationship in the UK.. This research gap is of particular concern in light of a recent study carried out by Floud and colleagues who determined that women with disability in England were nearly $40 \%$ less likely to attend routine breast screening. ${ }^{11}$ Although Floud et al provide robust, population-wide evidence of disparities in breast cancer screening uptake for women with disabilities, this study was limited to individuals who had previously attended breast screening. Given that previous attendance is a significant determinant of future attendance at screening, it is unclear whether these findings can be generalised to the wider body of individuals who are eligible for breast cancer screening. ${ }^{26,27}$

With the prevalence of disability projected to rise with the ageing population, gaining a better understanding of the relationship between disability and breast screening attendance is a central factor not only in overcoming the inequalities in screening access, but is essential in the drive to reduce the overall morbidity and mortality associated with breast cancer. ${ }^{28}$ As such, this paper aims to undertake a more generalisable population-wide study to determine whether chronic physical disabilities are associated with reduced uptake of routine breast cancer screening in the UK. More specifically:

1) To examine the overall association between having any physical disability and participation in breast screening.

2) To examine the association between different types of physical disability and multimorbidity on participation in breast screening.

3) To investigate whether the effect of physical disability on screening attendance is modified by social factors such as marital status and car access. 


\section{Methods}

\section{Data Sources and Measures}

Breast screening records:

Breast screening data for all women invited to attend routine breast screening through the Northern Ireland Breast Screening Programme in the three-year screening cycle following the 2011 Census was extracted from the National Breast Screening System (NBSS). Attendance was recorded as a binary yes/no variable. In the UK, women aged between 50-70 are invited to attend screening once every three years. However, individuals who do not turn up for their original screening appointment are sent a second invitation several weeks later. In this case, individuals who attended their subsequent appointment were classified as attenders. These were subsequently linked to the Northern Ireland Longitudinal Study (NILS) via encrypted Health and Care numbers to produce a de-identified research dataset.

The Northern Ireland Longitudinal Study:

The NILS is a large-scale data-linkage study containing information on approximately $28 \%$ of the population of Northern Ireland ( 508,000 people). NILS members are drawn from the Northern Ireland Health Card Registration System (the centralised system containing information on individuals registered to receive health and social care on the NHS) on the basis of birth date - anyone with one of 104 pre-designated birth days is included in the cohort. Additional information including vital event, such as births, deaths and marriages, migration data, as well as data from the 1981, 1991, 2001 and 2011 Census are also linked to the NILS core database. A more detailed overview of the NILS has been presented previously. ${ }^{29}$

Cohort Attributes:

All individual, household and area level cohort attributes were drawn from the 2011 Census within the NILS core database. Variables to be included in the model were selected based on previous evidence of association with breast screening uptake. Age at the 2011 Census was categorised as 5 different age bands: 'under 50', '50-54', '55-59', '60-64', and '65-70'. The 'under 50' group was included to incorporate women who reached eligibility for breast screening in the three years following the 2011 Census. Marital status was classified as 'currently married', 'separated, widowed or divorced', or 'single (never married)'. National- 
Statistics Socio-Economic Status (NSSEC) combines occupation with employment status to provide an indication of socioeconomic position. ${ }^{30}$ In the 2011 census, NSSEC was calculated based on an individual's most recent period of employment so that estimates could be made for retired or short-term unemployed individuals. For the purposes of the study, NSSEC was divided into 'managerial, administrative and professional', 'intermediate', 'own account', 'lower supervisory and technical', 'routine and semi-routine', and 'never worked, were full-time students, or long term unemployed'. Measures of housing tenure (owner, private renter, or social renter), educational attainment (degree or higher, up to A-Level, up to GCSE, or none) and number of cars or vans in the household (two or more, one, or none) were included as supplementary indicators of social class, and number of cars also provided insight into means of accessing the screening clinic. Finally, an indicator of area of residence was included in which individuals were classed as living in the Belfast Metropolitan Area (BMA) or the rest of Northern Ireland.

\section{Measure of disability:}

In the 2011 Census, participants were asked, "Do you have any of the following conditions, which have lasted, or are expected to last, at least 12 months?", to which participants were asked to tick all that applied from a list of 12 options: (i) "deafness or partial hearing loss"; (ii) "blindness or partial sight loss"; (iii) "communication difficulty (a difficulty with speaking or making yourself understood)"; (iv) "a mobility or dexterity difficulty (a condition that substantially limits one or more basic physical activities such as walking, climbing stairs, lifting or carrying)"; (v) "a learning difficulty, an intellectual difficulty, or a social or behavioural difficulty"; (vi) "an emotional, psychological or mental health condition (such as depression or schizophrenia)"; (vii) "long-term pain or discomfort"; (viii) "shortness of breath or difficulty breathing (such as asthma)"; (ix) "frequent periods of confusion or memory loss"; (x) "a chronic illness (such as cancer, HIV, diabetes, heart disease or epilepsy"; (xi) "other condition"; (xii) or "no condition" were all possible responses. "Chronic illness" was excluded from the analyses to avoid crossover in answers i.e. the first nine responses could be considered 'symptoms' of a chronic illness e.g. someone who has a chronic illness such as arthritis is likely to also respond as having a mobility or dexterity difficulty. Similarly, "other condition” was also excluded as the lack of additional information prevents classification of the condition as a disability. The impact of poor mental health on screening uptake was not investigated in this study as this paper is exclusively examining the impact of physical disability. 
Final Cohort:

The final cohort consisted of 57,328 women aged between 48 and 70 at the 2011 Census who were invited for routine breast screening through the Northern Ireland NHSBSP in the threeyear screening cycle following the 2011 Census. The study was approved by the Office for Research Ethics Committee Northern Ireland (ORECNI), the local ethics committee in Northern Ireland (ORECNI no: 07/NIR01/90+5).

Statistical Analysis:

Descriptive statistics were employed to compare the socio-demographic characteristics of women with and without physical disability. Crude uptake rates were calculated to facilitate inter-group comparison. Uptake was calculated as the percentage of women who attended breast screening out of the total number of women invited for screening during the study period.

Logistic regression was utilised to calculate age-only and fully-adjusted odds ratios and $95 \%$ confidence intervals (CIs) for attendance at breast screening. Initially, logistic regression was employed to examine the overall impact of having any physical disability on participation in breast screening with gradual adjustment for socio-demographic confounders. To assess and compare the impact of specific types of physical disability on breast screening uptake, odds ratios were calculated for women with a single physical disability in isolation. For this investigation, a separate logistic regression model was produced for each type of disability included in the study against a common comparator (women with no physical disabilities). To disentangle the effect of having multiple physical disabilities on screening attendance, separate logistic regression models were generated to examine the impact of each type of physical disability on attendance against a common comparator (no physical disability), with further adjustment for the presence of all other types of physical disability as binary yes/no variables. Subsequently, an indicator of multimorbidity was employed to examine the impact of co-morbid disabilities on breast screening uptake.

Interaction terms were included in fully-adjusted models to determine whether the effect of disability on screening uptake was modified by marital status or car access. 


\section{Results}

\section{The overall impact of physical disability}

Overall, $35.8 \%$ of women in the sample reported having at least one physical disability (see Table 1). Long-term pain or discomfort was the most commonly reported physical disability (21.2\%), followed by mobility or dexterity difficulties (20.4\%), and shortness of breath or difficulty breathing (12.2\%). Women with a physical disability were more likely to be older, to be un-married, to live in rented accommodation, to have no access to a car, to be unemployed, to have no educational qualifications, and to live in the Belfast Metropolitan Area (B.M.A) (see Supplementary Table 1). In the age-only adjusted logistic regression models, women with a physical disability were $29 \%$ less likely to attend screening compared to their counterparts with no physical disability (OR 0.71, 95\% CI $0.68-0.74$ ). Further adjustment for marital status and socio-economic differences explained the majority of this effect, however, the negative influence of physical disability remained statistically significant with further adjustment for area of residence (OR 0.93, 95\% CI $0.89-0.98$ ).

Interaction terms were introduced into the model to determine whether marital status or car access offset the effect of having any physical disability on breast screening uptake.

However, no statistically significant interactions were observed (where $\mathrm{p}>0.05$ ).

Table 1: The likelihood of attending breast screening by physical disability status. Data show the odds ratios (ORs) and $95 \%$ confidence intervals of attending breast screening with gradual adjustment for socio-demographic characteristics.

\begin{tabular}{|c|c|c|c|c|c|c|}
\hline & $\begin{array}{l}\text { No. Invited } \\
\text { (\% cohort) }\end{array}$ & $\begin{array}{l}\text { No. Attended } \\
\text { (\% uptake) }\end{array}$ & $\begin{array}{c}\text { Age-Only } \\
\text { Adjusted ORs } \\
(95 \% \mathrm{CI})\end{array}$ & +Marital status & $\begin{array}{c}\text { +Socio-economic } \\
\text { status }^{\mathrm{a}}\end{array}$ & $\begin{array}{l}+ \text { Area of } \\
\text { residence }\end{array}$ \\
\hline $\begin{array}{l}\text { No physical } \\
\text { disability }\end{array}$ & $36,787(64.2)$ & $29,703(80.7)$ & 1.00 & 1.00 & 1.00 & 1.00 \\
\hline $\begin{array}{l}\text { Any physical } \\
\text { disability }\end{array}$ & $20,541(35.8)$ & $15,358(74.8)$ & $0.71(0.68-0.74)$ & $0.77(0.74-0.80)$ & $0.93(0.89-0.97)$ & $0.93(0.89-0.98)$ \\
\hline
\end{tabular}

aAdjusted for social class (NSSEC), housing tenure, number of cars in the household, and educational attainment.

Figures in bold indicate significance at $\mathrm{p}<0.05$ 
Supp Table 1: Socio-demographic characteristics of women in the cohort by physical disability status.

\begin{tabular}{|c|c|c|c|}
\hline & & $\begin{array}{l}\text { Any physical disability } \\
\qquad(\mathrm{N}=20,541)\end{array}$ & $\begin{array}{l}\text { No physical disability } \\
\qquad(\mathrm{N}=36,787)\end{array}$ \\
\hline \multirow{5}{*}{ Age } & Under 50 & $1,402(6.8)$ & $4,267(11.6)$ \\
\hline & $50-54$ & $4,628(22.5)$ & $11,376(30.9)$ \\
\hline & $55-59$ & $4,644(22.6)$ & $8,634(23.5$ \\
\hline & $60-64$ & $5,419(26.4)$ & $7,509(20.4)$ \\
\hline & $65-70$ & $4,448(21.7)$ & $5,001(13.6)$ \\
\hline \multirow{3}{*}{ Marital Status } & Married & $12,024(58.5)$ & $26,045(70.8)$ \\
\hline & Separated/widowed/divorced & $1,820(8.9)$ & $7,854(21.4)$ \\
\hline & Single (never married) & $6,697(32.6)$ & $2,888(7.9)$ \\
\hline \multirow{6}{*}{ NSSEC } & $\begin{array}{l}\text { Managerial, administrative and } \\
\text { professional }\end{array}$ & 4,092 (19.9) & $11,481(31.2)$ \\
\hline & Intermediate & $3,277(16.0)$ & $7,677(20.9)$ \\
\hline & Own account & $828(4.0)$ & $2,255(6.1)$ \\
\hline & Lower supervisory \& technical & $1,007(4.9)$ & $1,350(3.7)$ \\
\hline & Routine/semi-routine & $9,207(44.8)$ & $12,282(33.4)$ \\
\hline & $\begin{array}{l}\text { Never worked/unemployed/FT } \\
\text { student }\end{array}$ & $2,130(10.4)$ & $1,741(4.7)$ \\
\hline \multirow{3}{*}{ Housing Tenure } & Owner & $14,330(69.8)$ & $31,884(86.7)$ \\
\hline & Private renter & $2,061(10.0)$ & $2,317(6.3)$ \\
\hline & Social renter & $4,150(20.2)$ & $2,586(7.0)$ \\
\hline \multirow{3}{*}{ Number of Cars } & Two or more & $7056(34.4)$ & $20538(558)$ \\
\hline & One & $8,883(43.3)$ & $12,695(34.5)$ \\
\hline & None & $4,602(22.4)$ & $3,554(9.7)$ \\
\hline \multirow{4}{*}{$\begin{array}{l}\text { Educational } \\
\text { Attainment }\end{array}$} & Degree or higher & $3,267(15.9)$ & $10,064(27.4)$ \\
\hline & Up to A-Level & $1,076(5.2)$ & $2,892(7.9)$ \\
\hline & Up to GCSE & $4,360(21.2)$ & $10,282(28.0)$ \\
\hline & None & $11,838(57.6)$ & $13,549(36.8)$ \\
\hline \multirow{2}{*}{ Area of Residence } & Rest of Northern Ireland & $13,100(63.8)$ & $25,020(68.0$ \\
\hline & Belfast Metropolitan Area (B.M.A) & $7,441(36.2)$ & $11,767(32.0)$ \\
\hline
\end{tabular}




\section{The impact of having a single physical disability in isolation}

$17.3 \%$ of women reported having a single physical disability in isolation (see Table 2). Of these women, long-term pain or discomfort was the most commonly reported physical disability (5.6\%). Although initial comparison of the crude uptake rates revealed lower attendance for all types of physical disability except deafness or partial hearing, the fullyadjusted logistic regression models revealed that only mobility or dexterity difficulties were associated with significantly reduced odds of attending screening (OR 0.88, 95\% CI 0.80 0.97), although overadjustment for factors such as car access and social class (which may not be applicable covariates for individuals with particular physical disabilities e.g. car access in individuals who report blindness or partial sight loss) potentially explains this observation.

There was some evidence that women with blindness or partial sight loss who were single were less likely to attend screening compared to those who were married (OR $0.28,95 \% \mathrm{CI}$ $0.12-0.63, \mathrm{p}=0.002$ ), however, no significant interaction effects were observed for any other types of disability. 
Table 2: Effect of single physical disabilities on screening attendance: results represent the numbers and proportions of people with single physical disabilities, uptake rates and ORs $(95 \%$ CI) of attending screening, from separate logistic regression models comparing each physical disability against people with no physical disability.

\begin{tabular}{|c|c|c|c|c|}
\hline Type of Disability & $\begin{array}{l}\text { No. Invited } \\
\text { (\% cohort) }\end{array}$ & $\begin{array}{l}\text { No. Attended (\% } \\
\text { uptake) }\end{array}$ & $\begin{array}{l}\text { Age-Only Adjusted } \\
\text { ORs }(95 \% \mathrm{CI})\end{array}$ & $\begin{array}{c}\text { Fully-Adjusted ORs }{ }^{\mathrm{a}} \\
(95 \% \mathrm{CI})\end{array}$ \\
\hline No physical disability & $36,787(64.2)$ & $29,703(80.7)$ & 1.00 & 1.00 \\
\hline Communication difficulty & $40(0.1)$ & $\mathrm{n} / \mathrm{a}$ & $0.70(0.34-1.43)$ & $0.99(0.48-2.08)$ \\
\hline $\begin{array}{l}\text { Long-term pain or } \\
\text { discomfort }\end{array}$ & $3,234(5.6)$ & 2,583 (79.9) & $0.95(0.87-1.04)$ & $1.09(0.99-1.19)$ \\
\hline $\begin{array}{l}\text { Blindness or partial sight } \\
\text { loss }\end{array}$ & $269(0.5)$ & 209 (77.7) & $0.85(0.64-1.14)$ & $1.05(0.78-1.41)$ \\
\hline $\begin{array}{l}\text { Mobility or dexterity } \\
\text { difficulty }\end{array}$ & $2,490(4.3)$ & $1,860(74.7)$ & $0.72(0.65-0.89)$ & $0.88(0.80-0.97)$ \\
\hline $\begin{array}{l}\text { Frequent periods of } \\
\text { confusion or memory loss }\end{array}$ & $136(0.2)$ & $95(69.9)$ & $0.56(0.39-0.81)$ & $0.78(0.53-1.14)$ \\
\hline $\begin{array}{l}\text { Shortness of breath or } \\
\text { difficulty breathing }\end{array}$ & $2,418(4.2)$ & $1,874(77.5)$ & $0.83(0.75-0.91)$ & $0.98(0.88-1.09)$ \\
\hline $\begin{array}{l}\text { Deafness or partial hearing } \\
\text { loss }\end{array}$ & $1,269(2.2)$ & $1,041(82.0)$ & $1.11(0.96-1.29)$ & $1.18(1.01-1.36)$ \\
\hline $\begin{array}{l}\text { Learning difficulty, } \\
\text { intellectual difficulty, or a } \\
\text { social or behavioural } \\
\text { difficulty }\end{array}$ & $100(0.2)$ & $73(73.0)$ & $0.64(0.41-0.99)$ & $1.45(0.91-2.30)$ \\
\hline
\end{tabular}

\section{The effect of physical disability in combination}

Logistic regression was employed to examine the impact of different types of physical disability allowing for the presence of multimorbidity (see Table 3). In the age-only adjusted models, having any of the examined physical disability types were associated with significantly reduced attendance at breast screening compared to those with no physical disability. With further adjustment for socio-demographic characteristics, having frequent periods of memory loss or confusion (OR $0.75,95 \%$ CI $0.66-0.85$ ), communication difficulty (OR $0.80,95 \%$ CI $0.67-0.96$ ), a mobility or dexterity difficulty (OR $0.85,95 \%$ CI $0.80-0.89$ ), shortness of breath or difficulty breathing (OR $0.90,95 \%$ CI $0.85-0.96$ ), or long-term pain or discomfort (OR $0.93,95 \%$ CI $0.88-0.98$ ) were associated with 
significantly reduced attendance at screening compared to those with no physical disability. However, these associations were attenuated considerably with adjustment for the presence of other physical disabilities and only mobility or dexterity difficulties (OR $0.88,95 \%$ CI $0.81-$ 0.95 ) and frequent periods of confusion or memory loss OR $0.76,95 \%$ CI $0.58-1.00$ ) remained significant determinants of reduced attendance at screening.

There was some evidence that participation in screening was lower for those with deafness or partial hearing loss who were single compared to their counterparts who were married (OR $0.65,95 \%$ CI $0.47-0.88, p=0.006$ ), however there was no evidence that being married or having access to a car modified the effect of any other type of disability on screening uptake. 
Table 3. The association between different types of physical disability and screening attendance: results represent ORs ( $95 \%$ CIs) of attending screening compared to those with no physical disability.

\begin{tabular}{|c|c|c|c|c|c|}
\hline & $\begin{array}{l}\text { No. Invited ( } \% \\
\text { cohort) }\end{array}$ & $\begin{array}{l}\text { No. Attended } \\
\text { (\% uptake) }\end{array}$ & $\begin{array}{l}\text { Age-Only Adjusted } \\
\text { ORs }(95 \% \mathrm{CI})\end{array}$ & $\begin{array}{l}\text { Fully-Adjusted } \\
\text { ORs }^{\mathrm{a}}(95 \% \mathrm{CI})\end{array}$ & $\begin{array}{l}\text { +Adjustment for all } \\
\text { other disabilities }^{\mathrm{b}}\end{array}$ \\
\hline No physical disability & $36,787(64.2)$ & $29,703(80.7)$ & 1.00 & 1.00 & 1.00 \\
\hline $\begin{array}{c}\text { Communication } \\
\text { difficulty }\end{array}$ & $551(1.0)$ & $363(65.9)$ & $0.46(0.38-0.55)$ & $0.80(0.67-0.97)$ & $0.96(0.64-1.45)$ \\
\hline $\begin{array}{l}\text { Long-term pain or } \\
\text { discomfort }\end{array}$ & $12,155(21.2)$ & $9,040(74.4)$ & $0.70(0.66-0.73)$ & $0.93(0.88-0.98)$ & $1.12(1.03-1.22)$ \\
\hline $\begin{array}{c}\text { Blindness or partial sight } \\
\text { loss }\end{array}$ & $920(1.6)$ & $666(72.4)$ & $0.64(0.55-0.74)$ & $0.88(0.76-1.03)$ & $1.19(0.92-1.54)$ \\
\hline $\begin{array}{c}\text { Mobility or dexterity } \\
\text { difficulty }\end{array}$ & $11,695(20.4)$ & 8,413 (71.9) & $0.62(0.59-0.65)$ & $0.85(0.80-0.89)$ & $0.88(0.81-0.95)$ \\
\hline $\begin{array}{c}\text { Frequent periods of } \\
\text { confusion or memory } \\
\text { loss }\end{array}$ & $1,245(2.2)$ & $815(65.5)$ & $0.45(0.40-0.51)$ & $0.75(0.66-0.85)$ & $0.76(0.58-1.00)$ \\
\hline $\begin{array}{l}\text { Shortness of breath or } \\
\text { difficulty breathing }\end{array}$ & 6,999 (12.2) & $5,009(71.6)$ & $0.61(0.57-0.64)$ & $0.86(0.81-0.92)$ & $0.97(0.89-1.07)$ \\
\hline $\begin{array}{c}\text { Deafness or partial } \\
\text { hearing loss }\end{array}$ & $2,975(5.2)$ & $2,314(77.8)$ & $0.86(0.78-0.94)$ & $1.08(0.98-1.19)$ & $1.19(1.04-1.36)$ \\
\hline $\begin{array}{l}\text { Learning difficulty, } \\
\text { intellectual difficulty, or } \\
\text { a social or behavioural } \\
\text { difficulty }\end{array}$ & $483(0.8)$ & $306(63.4)$ & $0.41(0.34-0.49)$ & $0.85(0.69-1.04)$ & $1.12(0.80-1.57)$ \\
\hline
\end{tabular}

CI: confidence interval: OR: odds ratios.

a Adjusted for age, marital status, NSSEC, housing tenure, number of cars, educational attainment, and area of residence.

b Adjusted for age, marital status, NSSEC, housing tenure, number of cars, educational attainment, area of residence, and the presence of all other disabilities in the model.

Figures in bold indicate significance at $\mathrm{p}<0.05$. 


\section{The impact of multimorbidity}

Amongst those who reported physical disability, multimorbidity was more common than singular disability; whilst $17.4 \%$ reported having only one physical disability, $18.5 \%$ of individuals in the cohort reported multimorbidity (see Table 4). Although a strong doseresponse effect was observed with increasing number of physical disabilities, the magnitude of the effect was attenuated with adjustment for other socio-demographic factors. After adjustment for these attributes, women with two or three physical disabilities were $9 \%$ (OR $0.91,95 \%$ CI $0.85-0.97$ ) and $16 \%$ (OR $0.84,95 \%$ CI 0.77 - 0.91), respectively, less likely to attend screening compared to those with no physical disabilities. Women with four or more physical disabilities were over $25 \%$ less likely to attend (OR $0.76,95 \%$ CI $0.66-0.86$ ).

There was no evidence that the effect of multimorbidity on breast screening uptake was modified by car access or marital status $(\mathrm{p}>0.05)$.

Table 4: The effect of multimorbidity on attendance rates: results represent the numbers and proportions of women with one, two, three, or four+ physical disabilities, uptake rates and the odds ratio (OR) and $95 \%$ confidence intervals of attending screening.

\begin{tabular}{|c|c|c|c|c|}
\hline & $\begin{array}{l}\text { No. Invited (\% } \\
\text { pop) }\end{array}$ & $\begin{array}{l}\text { No. Attended (\% } \\
\text { Uptake) }\end{array}$ & $\begin{array}{c}\text { Age-Only Adjusted } \\
\text { ORs }(95 \% \text { CI })\end{array}$ & $\begin{array}{l}\text { Fully-Adjusted ORs }{ }^{\mathrm{a}} \\
\qquad(95 \% \mathrm{CI})\end{array}$ \\
\hline No physical disability & $36,787(64.2)$ & $29,703(80.7)$ & 1.00 & 1.00 \\
\hline One physical disability & $9,956(17.4)$ & $7,765(78.0)$ & $0.85(0.81-0.90)$ & $1.01(0.96-1.07)$ \\
\hline $\begin{array}{l}\text { Two physical } \\
\text { disabilities }\end{array}$ & $6,295(11.0)$ & $4,654(73.9)$ & $0.68(0.64-0.72)$ & $0.91(0.85-0.97)$ \\
\hline $\begin{array}{l}\text { Threephysical } \\
\text { disabilities }\end{array}$ & $3,127(5.5)$ & $2,183(69.8)$ & $0.56(0.52-0.61)$ & $0.84(0.77-0.91)$ \\
\hline $\begin{array}{l}\text { Four+ physical } \\
\text { disabilities }\end{array}$ & $1,163(2.0)$ & $756(65.0)$ & $0.45(0.39-0.51)$ & $0.76(0.66-0.86)$ \\
\hline
\end{tabular}

CI: confidence interval.

${ }^{a}$ Adjusted for age, marital status, NSSEC, housing tenure, number of cars, educational attainment, and area of residence.

Figures in bold indicate significance at $\mathrm{p}<0.05$. 


\section{Discussion}

The findings of this study provide population-wide evidence of disparities in breast cancer screening uptake for women with physical disabilities in the United Kingdom (UK).

Attendance at screening was not only influenced by the presence of a disability, but also the type of disability and the number of comorbid disabilities.

The results of this study indicate that overall, women with any physical disability are $7 \%$ less likely to attend screening compared to women with no physical disability, although the true effect size is likely much greater given the challenges in appropriately adjusting for confounders across the various types of disability examined. Although there is a severe lack of research on the impact of disabilities on breast screening attendance in the UK, this finding builds on a previous study by Floud and colleagues who observed a 36\% reduction in the odds of attending breast screening in women with any disability. ${ }^{11}$ Although a much smaller effect size was observed in the current study, this can be explained by the inclusion of a more limited range of disability types and the ability to apply 'thresholds' in their study which limited the analysis to more severe forms of disabilities.

Although there was evidence that some types of isolated physical disabilities more greatly impacted a woman's likelihood of attending screening compared to others, with the exception of individuals with mobility or dexterity difficulties, the significance of these associations was fully attenuated with adjustment for socio-demographic factors. However, given the extensive variation in the socio-demographic characteristics of individuals across the spectrum of disability and the resulting difficulty in universally controlling for confounders, it is important to consider the role of overadjustment in these findings. For example, adjusting for factors such as educational attainment and socio-economic status in individuals with learning disabilities given the well-documented inequalities in access to education and employment likely underestimates the true extent of this association. ${ }^{23}$

Further analyses accounting for the presence of comorbid physical disabilities revealed disparities in uptake by type of disability examined, in particular, for women with mobility or dexterity difficulties, frequent periods of confusion or memory loss, or shortness of breath or difficulty breathing. Whilst there is also a dearth of literature examining the impact of specific types of disability on screening attendance, these findings generally corroborate the observations made in the existing literature. ${ }^{11,25}$ 
Multimorbidity was also an important determinant of screening uptake. As previously noted by Floud et $\mathrm{al}^{11}$ and Chan et $\mathrm{al}^{17}$, a dose-response relationship was evident with increasing number of disabilities; having two or more physical disabilities was significantly and cumulatively associated with lower breast screening attendance which can presumably be attributed to the increased degree of activity limitation imposed by having comorbid disabilities.

The findings from this study are reflective of the qualitative literature examining the barriers to obtaining screening for women with disabilities, and together, provide further clarification of the underlying explanation for the disparities in uptake. ${ }^{31-33}$. In a review of the literature, Ramjan et $\mathrm{al}^{22}$ highlighted a lack of accessible features at screening units, healthcare workers attitudes and knowledge about disabilities, and difficulties in standing unaided during screening mammography as key deterrents to attending screening. This likely explains the larger disparities observed for particular types of disability e.g. mobility or dexterity difficulties, as the limitations of certain disabilities will impose greater obstacles to participation than others.

Further analyses were employed to determine whether the additional social and physical support i.e. having the support of a partner, and having access to a car, modify the association between having a physical disability and attendance at screening. Notably, there was no evidence to suggest that car access or marital status modified the overall impact of having any physical disability on uptake. The findings of the current study contrast with those by Floud et al who observed that individuals with disability who had no access to a car were significantly less likely to attend compared to similar individuals who had access to a car although the inclusion of a broader range of disabilities, and an inability to adjust for severity in the current study may have contributed to the 'dilution' of the observed disparities. There was some evidence that for those with blindness or partial sight loss, not being married contributed to further reductions in uptake, however, no effect modification was observed for any other specific disability. Although this findingsuggests that individuals with disability are universally affected by inequalities in screening access, it is possible that the study lacked statistical power to detect any significant interaction effects in this part of the analyses. 


\section{Strengths and Limitations}

The design of this study provided a unique opportunity to prospectively examine the association between physical disability and breast cancer screening at a population-wide level. In contrast to previous research in the UK, the inclusion of previous non-attenders in the current study increases the generalisability of these findings to the wider body of women eligible for breast screening. The use of validated screening records and an indicator of disability reported prior to screening invitation surmounted the issue of recall-bias. The primary limitation of the study is the use of a self-reported measure of disability. As a result, responses were subject to an individual's perception of their physical health. Furthermore, the lack of information on the severity of disability limited the scope of the analyses and possibly contributed to an underestimation of the overall impact of disability on screening uptake through the inclusion of less limiting conditions.

\section{Conclusion}

This study comprises one of the few studies examining the impact of disability on breast cancer screening uptake in the UK. Our findings highlight concerning disparities in attendance at breast cancer screening for women with physical disability, particularly for those with multimorbidity. This evidence must be carefully considered by policy makers to ensure that targeted interventions may be put in place to ensure equity in accessing preventative screening for all women, especially given the projected rise in disability associated with the ageing population. 


\section{References}

1. About breast cancer | Cancer Research UK, http://www.cancerresearchuk.org/aboutcancer/breast-cancer/about (accessed 10 December 2017).

2. Marmot MG, Altman DG, Cameron DA, et al. The benefits and harms of breast cancer screening: an independent review. Lancet 2012; 380: 1778-1786.

3. Centre for Cancer Prevention. Breast Screening Results from the NHSBSP 2012/13. London, http://webarchive.nationalarchives.gov.uk/20150506050650/http://www.cancerscreeni ng.nhs.uk//breastscreen/statistics.html (2014, accessed 19 March 2017).

4. Richards MA. The National Awareness and Early Diagnosis Initiative in England: assembling the evidence. Br J Cancer 2009; 101: S1-4.

5. Bansal N, Bhopal R, Steiner M, et al. Major ethnic group differences in breast cancer screening uptake in Scotland are not extinguished by adjustment for indices of geographical residence, area deprivation, long-term illness and education. Br J Cancer 2012; 106: 1361-1368.

6. Szczepura A, Price C, Gumber A. Breast and bowel cancer screening uptake patterns over 15 years for UK south Asian ethnic minority populations, corrected for differences in socio-demographic characteristics. BMC Public Health 2008; 8: 346.

7. O'Reilly D, Kinnear H, Rosato M, et al. Using record linkage to monitor equity and variation in screening programmes. BMC Med Res Methodol 2012; 12: 59.

8. Moser K, Patnick J, Beral V. Inequalities in reported use of breast and cervical screening in Great Britain: analysis of cross sectional survey data. BMJ 2009; 338: b2025.

9. Renshaw C, Jack RH, Dixon S, et al. Estimating attendance for breast cancer screening in ethnic groups in London. BMC Public Health 2010; 10: 157.

10. Coyle C, Kinnear H, Rosato M, et al. Do women who intermittently attend breast screening differ from those who attend every invitation and those who never attend? $J$ Med Screen 2014; 21: 98-103.

11. Floud S, Barnes I, Verfürden M, et al. Disability and participation in breast and bowel cancer screening in England: a large prospective study. Br J Cancer 2017; 117: 17111714.

12. Andresen EM, Peterson-Besse JJ, Krahn GL, et al. Pap, mammography, and clinical breast examination screening among women with disabilities: a systematic review. Women's Heal Issues 2013; 23: e205-e214.

13. Iezzoni LI, McCarthy EP, Davis RB, et al. Use of screening and preventive services among women with disabilities. Am J Med Qual 2001; 16: 135-144.

14. Horner-Johnson W, Dobbertin K, Iezzoni LI. Disparities in receipt of breast and cervical cancer screening for rural women age 18 to 64 with disabilities. Women's Heal Issues 2015; 25: 246-253.

15. Armour BS, Thierry JM, Wolf LA. State-level differences in breast and cervical cancer screening by disability status: United States, 2008. Women's Heal Issues 2009; 19: 406-414. 
16. Guilcher SJT, Lofters A, Glazier RH, et al. Level of disability, multi-morbidity and breast cancer screening: Does severity matter? Prev Med (Baltim) 2014; 67: 193-198.

17. Chan L, Doctor JN, MacLehose RF, et al. Do Medicare patients with disabilities receive preventive services? A population-based study. Arch Phys Med Rehabil 1999; 80: 642-646.

18. Diab ME, Johnston M V. Relationships between level of disability and receipt of preventive health services. Arch Phys Med Rehabil 2004; 85: 749-757.

19. Havercamp SM, Scandlin D, Roth M. Health Disparities among Adults with Developmental Disabilities, Adults with other Disabilities, and Adults Not Reporting Disability in North Carolina. Public Health Rep 2004; 119: 418-426.

20. Nosek MA, Howland CA. Breast and cervical cancer screening among women with physical disabilities. Arch Phys Med Rehabil 1997; 78: S39-44.

21. World Health Organisation. World Report on Disability, www.who.int/about/licensing/copyright_form/en/index.html (2011, accessed 13 March 2019).

22. Ramjan L, Cotton A, Algoso M, et al. Barriers to breast and cervical cancer screening for women with physical disability: a review. Women Health 2016; 56: 141-156.

23. Equality and Human Rights Commission. Being disabled in Britain, https://www.equalityhumanrights.com/sites/default/files/being-disabled-in-britain.pdf (2017, accessed 27 February 2019).

24. Gatrell A, Garnett S, Rigby J, et al. Uptake of screening for breast cancer in south Lancashire. Public Health 1998; 112: 297-301.

25. Iezzoni LI, McCarthy EP, Davis RB, et al. Mobility impairments and use of screening and preventive services. Am J Public Health 2000; 90: 955-61.

26. Jepson R, Clegg A, Forbes C, et al. The determinants of screening uptake and interventions for increasing uptake: a systematic review. Health Technol Assess 2000; 4: i-vii, 1-133.

27. Esteva M, Ripoll J, Leiva A, et al. Determinants of non attendance to mammography program in a region with high voluntary health insurance coverage. BMC Public Health 2008; 13: 387.

28. Guzman-Castillo M, Ahmadi-Abhari S, Bandosz P, et al. Forecasted trends in disability and life expectancy in England and Wales up to 2025: a modelling study. Lancet Public Heal 2017; 2: e307-e313.

29. O'Reilly D, Rosato M, Catney G, et al. Cohort description: The Northern Ireland Longitudinal Study (NILS). Int J Epidemiol 2012; 41: 634-641.

30. Rose D, Pevalin D, O'Reilly K. The National Statistics Socio-Economic Classification : origins, development and use. Palgrave Macmillan, https://www.palgrave.com/gb/book/9781403996480 (2005, accessed 22 March 2018).

31. Mele N, Archer J, Pusch BD. Access to breast cancer screening services for women with disabilities. J Obstet Gynecol Neonatal Nurs 2005; 34: 453-464.

32. Angus J, Seto L, Barry N, et al. Access to cancer screening for women with mobility disabilities. J Cancer Educ 2012; 27: 75-82.

33. Peters K, Cotton A. Environmental, structural and process barriers in breast cancer 
screening for women with physical disability: a qualitative study. Radiography 2016; 22: e184-e189. 
Ethical approval: The study was approved by the Office for Research Ethics Committee Northern Ireland (ORECNI), the local ethics committee in Northern Ireland (ORECNI no: 07/NIR01/90+5).

Acknowledgements: The help provided by the staff of the Northern Ireland Longitudinal Study (NILS) and the NILS Research Support Unit is acknowledged. The NILS is funded by the Health and Social Care Research and Development Division of the Public Health Agency (HSC R\&D Division) and NISRA. The NILS-RSU is funded by the ESRC and the Northern Ireland Government. The authors alone are responsible for the interpretation of the data and any views or opinions presented are solely those of the author and do not necessarily represent those of NISRA/NILS.

\section{Declarations of conflicting interest: None}

Funding: This work was funded by a studentship from the Department for the Economy (DFE), formerly the Department for Employment and Learning (DEL). 